\title{
Nano- $\mathrm{TiO}_{2}$ Phototoxicity in Fresh and Seawater: Daphnia magna and Artemia sp. as Proxies
}

\author{
Ana C. Soler de la Vega ${ }^{1}$, Alberto Cruz-Alcalde ${ }^{2}$, Carmen Sans Mazón ${ }^{2} \mathbb{C}$, Carlos Barata Martí ${ }^{1}$ \\ and M. Silvia Diaz-Cruz ${ }^{1, *(\mathbb{D})}$ \\ 1 Department of Environmental Chemistry, Institute of Environmental Assessment and Water Research of the \\ Spanish Council for Scientific Research (IDAEA-CSIC), Excellence Center Severo Ochoa, Jordi Girona 18-26, \\ 08034 Barcelona, Spain; asvqam@cid.csic.es (A.C.S.d.1.V.); cbmqam@cid.csic.es (C.B.M.) \\ 2 Department of Chemical Engineering and Analytical Chemistry, Faculty of Chemistry, Universitat de \\ Barcelona (UB), Martí i Franqués 1, 08028 Barcelona, Spain; alberto.cruz@ub.edu (A.C.-A.); \\ carmesans@ub.edu (C.S.M.) \\ * Correspondence: silvia.diaz@idaea.csic.es
}

Citation: Soler de la Vega, A.C. Cruz-Alcalde, A.; Sans Mazón, C.; Barata Martí, C.; Diaz-Cruz, M.S. Nano-TiO ${ }_{2}$ Phototoxicity in Fresh and Seawater: Daphnia magna and Artemia sp. as Proxies. Water 2021, 13, 55. https:/ / doi.org/10.3390/w13010055

Received: 11 November 2020 Accepted: 22 December 2020 Published: 30 December 2020

Publisher's Note: MDPI stays neutral with regard to jurisdictional clai$\mathrm{ms}$ in published maps and institutional affiliations.

Copyright: (C) 2020 by the authors. Licensee MDPI, Basel, Switzerland. This article is an open access article distributed under the terms and conditions of the Creative Commons Attribution (CC BY) license (https:// creativecommons.org/licenses/by/ $4.0 /)$.

\begin{abstract}
Nowadays, the industry is quite commonly using nanoparticles of titanium dioxide $\left(\mathrm{nTiO}_{2}\right)$ especially in sunscreens, due to its higher reflective index in comparison to micron size $\mathrm{TiO}_{2}$. Its high demand causes its widespread environmental occurrence, thus damaging the environment. The aquatic ecosystems are the most vulnerable to contamination by $\mathrm{nTiO}_{2}$. Like other engineered nanoparticles, $\mathrm{nTiO}_{2}$ has demonstrated generation of reactive oxygen species (ROS) and reactive halogen species (RHS) in the aquatic environment under UV radiation. This study investigated the toxicity of $\mathrm{nTiO}_{2}$ towards two aquatic indicator organisms, one from freshwater (Daphnia magna) and the other from seawater (Artemia sp.), under simulated solar radiation (SSR). Daphnia magna and Artemia sp. were co-exposed in $16 \mathrm{~h}$ SSR and $8 \mathrm{~h}$ darkness cycles to different concentrations of $\mathrm{nTiO}_{2}$. The estimated EC50 at $48 \mathrm{~h}$ for $D$. magna was $3.16 \mathrm{mg} \mathrm{nTiO}_{2} / \mathrm{L}$, whereas for $A$. sp. no toxic effects were observed. When we exposed these two organisms simultaneously to $48 \mathrm{~h}$ of prolonged SSR using higher $\mathrm{nTiO}_{2}$ concentrations, EC50 values of $7.60 \mathrm{mg} / \mathrm{L}$ and $5.59 \mathrm{mg} / \mathrm{L} \mathrm{nTiO}_{2}$ for D. magna and $A$. sp., respectively, were obtained. A complementary bioassay was carried out with $A$. sp., by exposing this organism to a mixture of $\mathrm{nTiO}_{2}$ and organic UV filters (benzophenone 3 (oxybenzone, $\mathrm{BP3})$, octocrylene (OC), and ethyl 4-aminobenzoate (EtPABA)), and then exposed to SSR. The results suggested that $\mathrm{nTiO}_{2}$ could potentially have negative impacts on these organisms, also this work outlines the different characteristics and interactions that may contribute to the mechanisms of environmental (in salted and freshwater) phototoxicity of $\mathrm{nTiO}_{2}$ and $\mathrm{UV}$ radiation, besides their interaction with organic compounds.
\end{abstract}

Keywords: nanosized inorganic sunscreen; phototoxicity; aquatic organisms; environmental hazard; reactive oxygen species (ROS); reactive halogen species (RHS)

\section{Introduction}

The use of nanoparticles of titanium dioxide $\left(\mathrm{nTiO}_{2}\right)$ has increased significantly in recent years. It has been predicted that the global market for nanotechnology products would achieve 3 trillion \$ by 2020 [1]. Piccinno documented the estimated worldwide production of titanium dioxide nanoparticles $\left(\mathrm{nTiO}_{2}\right)$ at approximately $5000 \mathrm{t} /$ year in 2006-2010 and 10,000 $\mathrm{t}$ /year in 2011-2014 with an increase in the production of this nanomaterial by 2025 [2].

This impressive increase is mainly due to the demand for this metal oxide in the paper, paint, coating, cosmetics, food, and plastic industries. $\mathrm{TiO}_{2}$ is a white substance commonly used as a whitening or brightening agent that is generally synthesized in different crystalline forms, mainly anatase and rutile. It is also used in water purification processes due to the high photocatalytic activity showed by specific $n \mathrm{TiO}_{2}$ formulations 
such as the well-known Degussa P-25, which contains anatase and rutile phases in a ratio of about 3:1 [3].

Nano-size $\mathrm{TiO}_{2}$ is increasingly used as a mineral sunscreen to protect the skin from both ultraviolet light $\mathrm{A}$ and ultraviolet light $\mathrm{B}$ radiation, because of its broad UV spectrumattenuation characteristics. When it is formulated in nano-size, the protection significantly improves as only a tiny proportion of UV rays can pass through the sunscreen film without hitting a particle [4-6]. It is expected that commercial sunscreens contain a mixture of physical and chemical UV filters to produce a broader spectrum of protection [7].

After use, $\mathrm{nTiO}_{2}$ is discharged into the sewage system and subsequently released into surface waters, where it can interact with living organisms [8]. As both solar irradiance (i.e., the amount of sunlight received by Earth's surface) and $\mathrm{nTiO}_{2}$ accumulation in the environment increase year after year, there is a high probability that $\mathrm{UV}$ radiation and $\mathrm{nTiO}_{2}$ interact in the aquatic environment. This fact, in turn, increases the concerns about the environmental fate and ecotoxicity of this compound [9]. The process of $\mathrm{nTiO}_{2}$ activation by UV light and subsequent formation of reactive oxygen species (ROS), such as superoxide radicals $\left(\mathrm{O}_{2}{ }^{\bullet-}\right)$, hydroxyl radicals $\left({ }^{\bullet} \mathrm{OH}\right)$, and singlet oxygen $\left({ }^{1} \mathrm{O}_{2}\right)$ in water is relatively well known [10-12]. However, in the presence of high concentrations of salts, as is the case in seawater, the mechanisms driving their interaction are still not fully understood although there is some evidence that reactive halogen species (RHS) may be produced $[13,14]$. ROS and RHS can cause oxidative stress to cells in the aquatic environment [15], hence damaging cell membranes and oxidizing proteins [16].

Previous studies have shown the phototoxic effects on D. magna and Artemia sp. simultaneously exposed to $\mathrm{nTiO}_{2}$ and radiation $[17,18]$.

In the present study, the combined effect of $\mathrm{nTiO}_{2}$ and simulated solar radiation towards two aquatic organisms, i.e., D. magna and $A$. sp. as a proxy of freshwater and seawater organisms, respectively, was investigated and the EC50 were calculated. In addition, Artemia sp. was exposed to a mixture of organic UV filters, $\mathrm{nTiO}_{2}$, and UV solar radiation to identify the toxicity dynamics.

\section{Materials and Methods}

\subsection{Instrumentation}

A Microscope Leica EZ4 (Leica Microsistemas S.L.U., L'Hospitalet de Llobregat, Barcelona, Spain) was used to determine mortality in the bioassays with Artemia sp.

A solar simulator chamber XENOTERM-1500RF chamber (CCI, Mataró, Spain) was employed to simulate UV sunlight radiation. An ultrasounds bath (SELECTA, Barcelona, Spain) was used to shake the test solutions.

To determine the EC50 values, the mortality of the D. magna and A. sp., during exposure to the tested compounds, was normalized to the control mean percentage using Abbot's formula (2004). Normalized percentage values were log-transformed and fitted to the logistic regression model using Quest Graph ${ }^{\mathrm{TM}}$ EC50 Calculator (https:/ / www.aatbio. $\mathrm{com} /$ tools/ec50-calculator/).

\section{2. $n \mathrm{TiO}_{2}$ and Organic Sunscreens}

The $\mathrm{nTiO}_{2}$ standard compound used (Sigma-Aldrich, Munich, Germany) had a particle size of $\leq 21 \mathrm{~nm}$, and $\geq$ a $99.5 \%$ trace metal basis. According to the manufacturer, the crystal phase of $\mathrm{nTiO}_{2}$ was a mixture of anatase and rutile (80:20). Transmission electron microscopy (TEM) and dynamic light scattering (DLS) were applied to characterize the $\mathrm{nTiO}_{2}$ and are presented elsewhere at Soler de la Vega [19].

The initial stock standard suspension of $\mathrm{nTiO}_{2}$ in the organism medium was shaken in an ultrasound bath for $30 \mathrm{~min}$ and left for $24 \mathrm{~h}$ under agitation in darkness before the preparation of solutions. The test solutions were prepared from the stock suspension still under agitation and further dispersed in the ultrasound bath for $15 \mathrm{~min}$ before exposure. This procedure increases dispersion and provides the maximum distribution of the nanoparticles. 
Immediately after the sonication, the appropriate aliquots were taken to prepare six suspensions at concentrations of $0.000018,0.01,0.1,1,10$, and $100 \mathrm{mg} / \mathrm{L}$ under the same bioassay conditions (dilution in the Daphnia or Artemia culture media).

The UV filters benzophenone 3 (oxybenzone, BP3) 98\% purity, octocrylene (OC) 97\% purity, and ethyl 4-aminobenzoate (EtPABA) 98\% purity were supplied by SigmaAldrich (Steinheim, Germany), and methanol (MeOH) was provided by Panreac Applichem (Castellar del Vallès, Barcelona, Spain).

At the time of the exposure, working mixture solutions containing BP3, OC, and EtPABA, at equal proportions ( $1 \mathrm{mg} / \mathrm{L}$ of each compound), were prepared in $\mathrm{MeOH}$ : water 20:80 (v:v). From this mixture solution and the $\mathrm{nTiO}_{2}$ stock solution, volumetric measurements were made to get the desired analyte concentration in purified water obtained from an Elix 3 coupled to a Milli-Q system from Millipore (Bedford, MA, USA). All test solutions were kept at $20 \pm 2{ }^{\circ} \mathrm{C}$ during the bioassays.

\subsection{Aquatic Organisms}

\subsubsection{Daphnia magna}

Parthenogenetic cultures of a single clone of D. magna (clone F) were used in the experiments. The photoperiod cycle was set to $16 \mathrm{~h}$ light: $8 \mathrm{~h}$ dark, at a controlled temperature of $20 \pm 1^{\circ} \mathrm{C}$. Bulk cultures of 10 adult females were maintained in $2 \mathrm{~L}$ medium at ratio levels $\left(5 \times 10^{5}\right.$ cells $/ \mathrm{mL}$ of Chlorella vulgaris) following the method of Barata [20]. Newborn individuals $(<24 \mathrm{~h}$ old) obtained from bulk cultures were used in all the exposure experiments.

The D. magna culture and exposure media were prepared using Milli $\mathrm{Q}$ water. The characteristics of the water used for the D. magna were as follows: $\mathrm{pH} 7.9 \pm 1$; conductivity $135 \pm 1 \mathrm{lS} / \mathrm{cm}$; total hardness $2.1 \mathrm{dGH}$; temperature $250 \pm 1{ }^{\circ} \mathrm{C}$; and dissolved oxygen (DO) $6 \pm 0.5 \mathrm{mg} / \mathrm{L}$.

\subsubsection{Artemia sp.}

Artemia sp. were obtained from commercial dry encysted eggs from Inve Aquaculture NV. (Hovel 91·B-9200, Dendermonde, Belgium). One hundred mg of Artemia sp. cysts were incubated in $1 \mathrm{~L}$ of artificial seawater prepared in Milli $\mathrm{Q}$ water dissolving Instant Ocean sea salt $(35 \mathrm{~g} / \mathrm{L} \mathrm{NaCl})$ for $24 \mathrm{~h}$ at $25^{\circ} \mathrm{C}$. The Artemia sp. produced were transferred with Pasteur pipettes to two glass flasks containing $200 \mathrm{~mL}$ of the synthetic seawater and immediately used for the assay. The characteristics of this water were as follows: $\mathrm{pH} 8.3 \pm 1$; conductivity $41 \pm 1 \mathrm{mS} / \mathrm{cm}$; temperature $25 \pm 1^{\circ} \mathrm{C}$; and DO $6 \pm 0.5 \mathrm{mg} / \mathrm{L}$.

The artificial sea salt used to prepare the organism medium was purchased from Instant Ocean Spectrum Brands 3001 Commerce St, Blacksburg, VA 24060, United States.

\section{Phototoxicity Experiments}

\subsection{Daphnia magna Bioassays}

The exposure procedure was adapted from the $48 \mathrm{~h}$ acute toxicity test using $D$. magna according to US Environmental Protection Agency (USEPA) standard operating procedure 2024.

The SSR experiments were conducted using a solar box equipped with a pulsedlight $1500 \mathrm{~W}$ Xenon lamp emulating the solar light spectrum, and an air-driven cooling system to adjust the temperature during irradiation. A glass filter located between the light and the irradiated plates served to cut off radiation with $\lambda<290 \mathrm{~nm}$, thus filtering the ultraviolet light $C$ radiation component emitted by the lamp, which is not characteristic of the sunlight arriving at the Earth. Petri dishes with $10 \mathrm{~mL}$ of the medium containing 10 D. magna individuals and $\mathrm{nTiO}_{2}$ were placed inside the solar box. The UV light fluence rate was determined to be $10.67 \mathrm{~W} / \mathrm{m}^{2}$ in the range $290-400 \mathrm{~nm}$, using o-nitrobenzaldehyde actinometry, according to Bustos [21].

Assays were conducted varying both the SSR time, 16 and $48 \mathrm{~h}$, as well as the concentration of $\mathrm{nTiO}_{2}$ i.e., 0 (control), 0.000018, 0.01, 0.1, 1, and 10. These concentration levels were selected considering the highest reported $\mathrm{nTiO}_{2}$ concentrations in water in Europe, according to Gottschalk [22]. Besides, we considered a higher concentration of $100 \mathrm{mg} / \mathrm{L}$, 
to potentially observe enhanced toxic effects. Control samples in the absence of $\mathrm{nTiO}_{2}$ and UV light exposure were also tested in all the experiments.

The bioassays were carried out in duplicate. The organisms were not fed during the experiments. All test solutions were kept at $20 \pm 2{ }^{\circ} \mathrm{C}$ during the exposure period. D. magna immobilization was recorded after $48 \mathrm{~h}$. At the end of the exposure, the number of individuals showed mobility in each recipient, and it was registered. The data obtained were used to determine the EC50 values.

UV exposure was conducted placing the organisms to a distance of $30 \mathrm{~cm}$ from the UV lamps, for a time interval of 16 and $48 \mathrm{~h}$. The exposure was made in Petri dishes containing the organism and the respective culture media. A control group was kept in the same room but without exposure to the UV radiation.

A preliminary test was carried out to assess the behavior of D. magna exposed to SSR, and to check the feasibility of the following tests.

\subsection{Artemia sp. Bioassays}

Exposure tests for Artemia sp. were carried out according to the Organisation for Economic Co-operation and Development 2004 (OECD ), using the same exposure protocol conducted for D. magna. A group of approx. $30 \mathrm{~A}$. sp. individuals were placed in individual containers and exposed to various concentrations and SSR in $96 \mathrm{~h}$ period test (3 replicates). Mortality was the endpoint of the test. Control samples without $\mathrm{nTiO}_{2}$ and UV light exposure were tested in all the experiments and was kept in the same room.

The simulated UV radiation experiments were conducted in the same solar box used for D. magna testing. Plates with salty media containing 30 Artemia sp. individuals and $2 \mathrm{~mL}$ of organism media and $\mathrm{nTiO}_{2}$ were placed inside the equipment. Assays were conducted varying both the $\mathrm{UV}$ irradiation time, 16 and $48 \mathrm{~h}$, as well as the concentration of $\mathrm{nTiO}_{2}$ i.e., 0 (control), $0.000018,0.01,0.1,1,10$, and $100 \mathrm{mg} / \mathrm{L}$.

UV exposure was conducted placing the organisms to a distance of $30 \mathrm{~cm}$ from the UV lamp, for a time interval of 16 and $48 \mathrm{~h}$. The exposure was made in Petri dishes containing the organism and the respective culture media. A control group was kept in the same room but without exposure to the UV radiation.

All test solutions were kept at $20 \pm 2{ }^{\circ} \mathrm{C}$ during the exposure period. A. sp. immobilization was recorded after $96 \mathrm{~h}$. In all Artemia sp. bioassays, the organisms were not fed during the exposure.

Since Artemia sp. in the first trial was resistant to the effects of $\mathrm{nTiO}_{2}$ in conjunction with SSR, it was decided to experiment with mixtures of the most used and most toxic compounds in sunscreens [23,24], in addition to exposing this organism to SSR.

Then, a second experiment was carried out, exposing Artemia sp. to $\mathrm{nTiO}_{2}$ in a mixture with the organic UV filters, BP3, EtPABA, and OC. These compounds were selected because they are commonly used in combination with $\mathrm{nTiO}_{2}$ in personal care products with sunlight protection. Exposure experiments containing $2 \mathrm{~mL}$ of organism media and 30 Artemia sp. individuals were made in triplicate in Petri dishes.

Finally, a third bioassay was carried out where Artemia sp. was exposed to increasing concentrations of $\mathrm{nTiO}_{2}$, i.e., 0 (control), $0.000018,0.01,0.1,1,5,10$, and $100 \mathrm{mg} / \mathrm{L}$, for $48 \mathrm{~h}$. The controls were (i) a solution not irradiated, (ii) a solution with the mixture of organic UV filters, and (iii) an organism's medium solution). Exposure experiments containing $2 \mathrm{~mL}$ of organism medium and 30 Artemia sp. individuals were made in triplicate.

\section{Results}

\subsection{Phototoxicity of $n \mathrm{TiO}_{2}$ towards D. magna}

A preliminary test was conducted in Petri dishes in $10 \mathrm{~mL}$ of the medium containing 10 D. magna individuals (2 replicates) and was classified into two groups, the control group (A), and the group exposed to SSR (B). Both groups were exposed $24 \mathrm{~h}$ before the assay started with three concentrations of $\mathrm{nTiO}_{2}$ (0 (control), $0.1,1$, and $10 \mathrm{mg} / \mathrm{L}$ ). 
Immediately after the $24 \mathrm{~h}$ doping, group A was incubated $6 \mathrm{~h}$ dark cycle, whereas group $\mathrm{B}$ was irradiated during the same time.

After UV light exposure of group B, the media in A and B were renewed, and acute toxicity tests ( $48 \mathrm{~h}$ exposure time) were conducted as described in Table 1.

Table 1. Total time of the preliminary bioassay, counting the first doping $24 \mathrm{~h}$, plus $6 \mathrm{~h}$ of the dark cycle and radiation, plus the acute toxicity test time 24 and $48 \mathrm{~h}$, resulting $78 \mathrm{~h}$ total.

\begin{tabular}{|c|c|c|c|c|c|c|c|}
\hline & \multicolumn{7}{|c|}{ Total Time Exposure Bioassay with Daphnia magna } \\
\hline & \multirow{2}{*}{$\begin{array}{c}\text { Concentration } \\
(\mathrm{mg} / \mathrm{L})\end{array}$} & \multirow{2}{*}{$\begin{array}{l}\text { Pre-Exposed to } \\
\text { nTiO }_{2}(\mathrm{~h})\end{array}$} & \multirow{2}{*}{ Dark Cicle } & \multirow{2}{*}{ SSR (h) } & \multicolumn{2}{|c|}{ Acute Toxicity Test (h) } & \multirow[b]{2}{*}{ Total Time (h) } \\
\hline & & & & & 24 & 48 & \\
\hline Group A & $0.1,1,10$ & 24 & 6 & $x$ & $\checkmark$ & $\checkmark$ & 78 \\
\hline Group B & $0.1,1,10$ & 24 & $x$ & 6 & $\checkmark$ & $\checkmark$ & 78 \\
\hline
\end{tabular}

The results of the preliminary test showed, on the one hand, that the low acute toxicity of $\mathrm{nTiO}_{2}$ towards D. magna suggested ingestion and accumulation, since only $<23 \%$ of immobilization at the $10 \mathrm{mg} / \mathrm{L}$ concentration was observed. At lower concentrations, i.e., $0.1 \mathrm{mg} / \mathrm{L}<15 \%$ of immobilization was observed.

In contrast, D. magna was exposed to the combined effect of $\mathrm{nTiO}_{2}$ and $\mathrm{UV}$ radiation, the toxicity increased to $30 \%$ of immobilization with $10 \mathrm{mg} / \mathrm{L} \mathrm{nTiO}_{2}$, at $0.1 \mathrm{mg} / \mathrm{L}$ the immobile individuals raised to $24 \%$.

It was clear that $\mathrm{nTiO}_{2}$ concentrations were harmful to D. magna, as in previous works when $D$. magna was exposed to $\mathrm{nTiO}_{2}$ [25-27]. Figure 1 shows that the immobilization ratio was $24 \%$ when D. magna was exposed to $\mathrm{nTiO}_{2}$ (group A), still, when this organism was exposed to both $\mathrm{nTiO}_{2}$ and SSR (group B) immobilization ratio was low, 30\%, suggesting a joined effect.

Given that the immobilization percentage increased in group B compared to group A, this provided the information needed to design the following bioassays.

In the second bioassay, D. magna was co-exposed to $\mathrm{nTiO}_{2}$ and SSR for $16 \mathrm{~h}$ and then kept in darkness for $8 \mathrm{~h}$ (mimicking a full solar day) before the acute toxicity test measurements. The exposure was made in Petri dishes containing $10 \mathrm{~mL}$ of the medium and $10 \mathrm{D}$. magna individuals. After $48 \mathrm{~h}$ exposure, the mobility in the control groups exceeded $90 \%$, in both cases: in the absence of $\mathrm{UV}$ radiation and $\mathrm{nTiO}_{2}$.

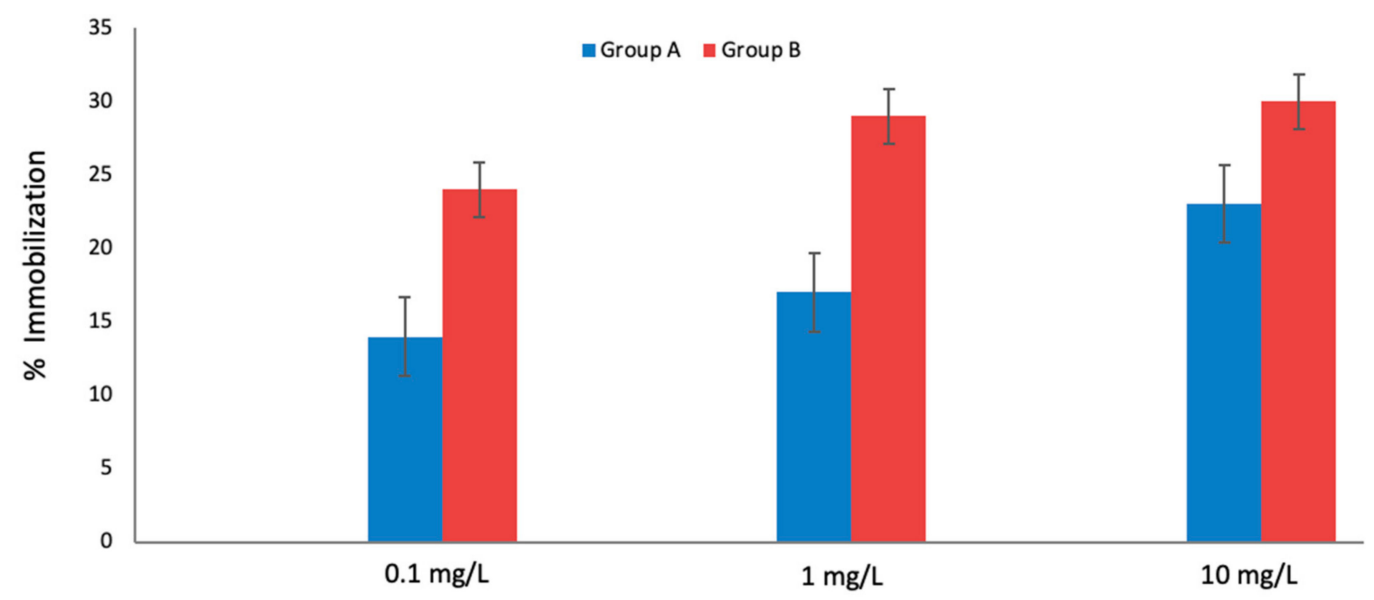

Concentration nTiO2

Figure 1. Groups A and B of D. magna exposed at three $\mathrm{nTiO}_{2}$ concentrations and then incubated $6 \mathrm{~h}$ (Group A) or exposed to UV irradiation (Group B). Furthermore, the acute toxicity test was conducted in $78 \mathrm{~h}$ total time in both groups. 
The results showed that the toxicity of $\mathrm{nTiO}_{2}$ towards $D$. magna increased with increased $\mathrm{nTiO}_{2}$ concentrations. As shown in Figure 2, at the lowest concentration $(0.000018 \mathrm{mg} / \mathrm{L})$, the mortality rate after $24 \mathrm{~h}$ was low, $20 \%$ a ratio of immobilization. At $10 \mathrm{mg} / \mathrm{L} \mathrm{nTiO}_{2}$, the mortality rate increased up to $60 \%$ with an EC50 value of $6.4 \mathrm{mg} / \mathrm{L}$. In the presence of SSR, the toxicity of $\mathrm{nTiO}_{2}$ to D. magna increased, suggesting that higher phototoxicity is displayed when the concentration of $\mathrm{nTiO}_{2}$ is high, which is in agreement with the results found when D. magna was only exposed to increasing $\mathrm{nTiO}_{2}$ concentrations. The results evidenced a concentration-dependent immobilization process.

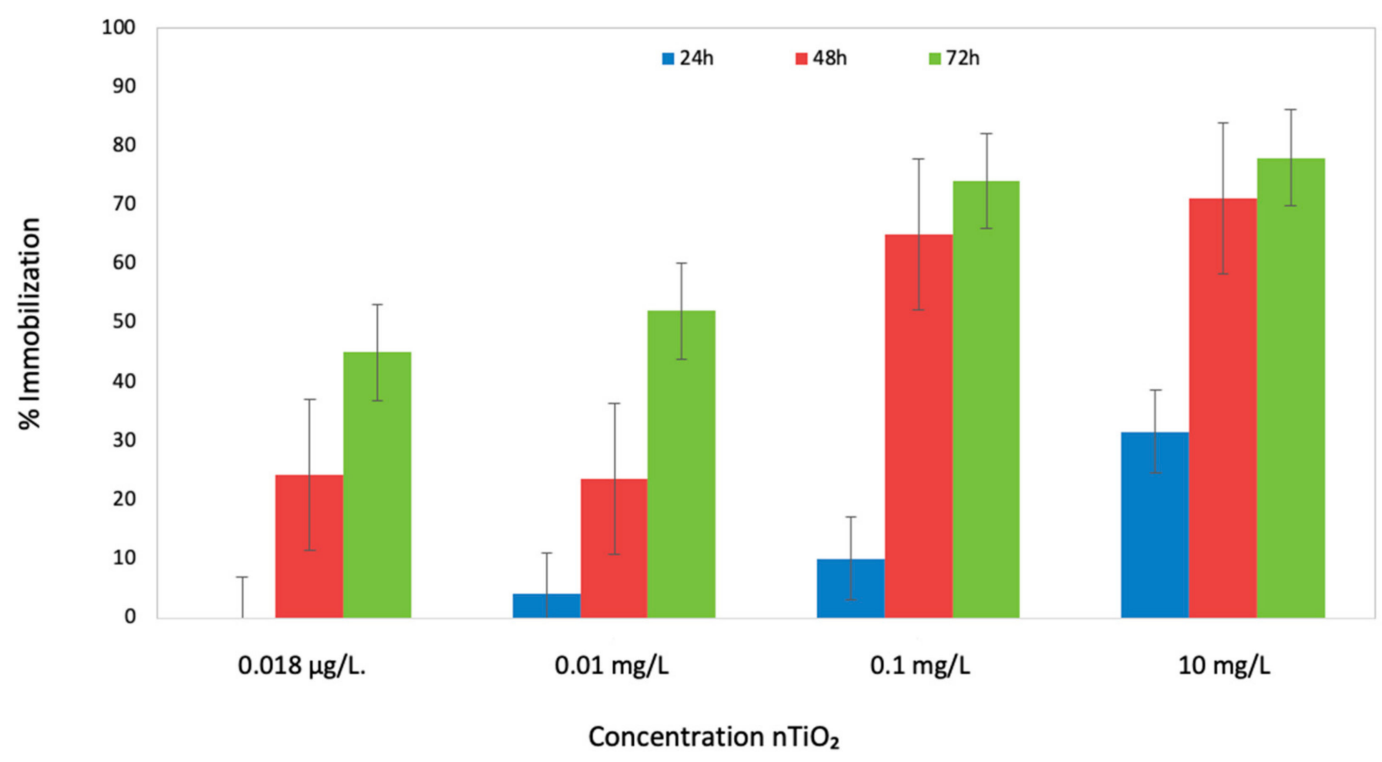

Figure 2. Percentage of immobilization for D. magna exposed to 24 and $48 \mathrm{~h}$ to SSR and $\mathrm{nTiO}_{2}$. The bars show the span of immobilization of the organism at $0.1,1,10$, and $100 \mathrm{mg} / \mathrm{L} \mathrm{nTiO}_{2}$.

In the third set of bioassays, D. magna was exposed in Petri dishes containing $10 \mathrm{~mL}$ of the medium and $10 \mathrm{D}$. magna individuals. The organisms were exposed to increasing concentrations of $\mathrm{nTiO}_{2}$ (0 (control), 0.000018, 0.1, 1, 10, and $100 \mathrm{mg} / \mathrm{L}$ ) and $48 \mathrm{~h}$ of UV radiation. In this bioassay, after the $24 \mathrm{~h}$ exposition, the irradiation was stopped for a few minutes to measure the immobilization. Then, the irradiation continued for an additional period of $24 \mathrm{~h}$. Hence, the total exposure time was $48 \mathrm{~h}$.

At the first $24 \mathrm{~h}$ of exposure, we observed that at 0.1 and $1 \mathrm{mg} / \mathrm{L} \mathrm{nTiO}_{2}$, the immobilization was $<20 \%$. Still, at $10 \mathrm{mg} / \mathrm{L}$ the immobilization increased to $42 \%$, and at the highest concentration, $100 \mathrm{mg} / \mathrm{L}, 75 \%$ of the individuals were immobile. Under these experimental conditions, the estimated EC50 was $12.98 \mathrm{mg} / \mathrm{L}$.

After $48 \mathrm{~h}$ exposition to continuous UV radiation, the immobilization at the two lower concentrations of $\mathrm{nTiO}_{2}, 0.1$, and $1 \mathrm{mg} / \mathrm{L}$ was $40 \%$. At $10 \mathrm{mg} / \mathrm{L}$ the immobilization was $77 \%$, and at the highest concentration, $100 \mathrm{mg} / \mathrm{L}, 100 \%$ of immobilization was observed. In this case, the estimated EC50 was $5.50 \mathrm{mg} / \mathrm{L}$, a relatively lower value than that calculated at the first $24 \mathrm{~h}$ UV irradiation, as shown in Figure 3. In all the acute toxicity tests with D. magna, survival in the control groups exceeded $90 \%$ after $48 \mathrm{~h}$ exposure.

\section{2. $n \mathrm{TiO}_{2}$ Phototoxicity towards Artemia sp.}

Artemia sp. was exposed to different concentrations (0 (control), 0.000018, 0.1, 1, and $10 \mathrm{mg} / \mathrm{L}$ ) of $\mathrm{nTiO}_{2}$ and $16 \mathrm{~h} \mathrm{SSR}$ and $8 \mathrm{~h}$ dark cycle. The toxicity under these conditions towards Artemia sp. was null. 


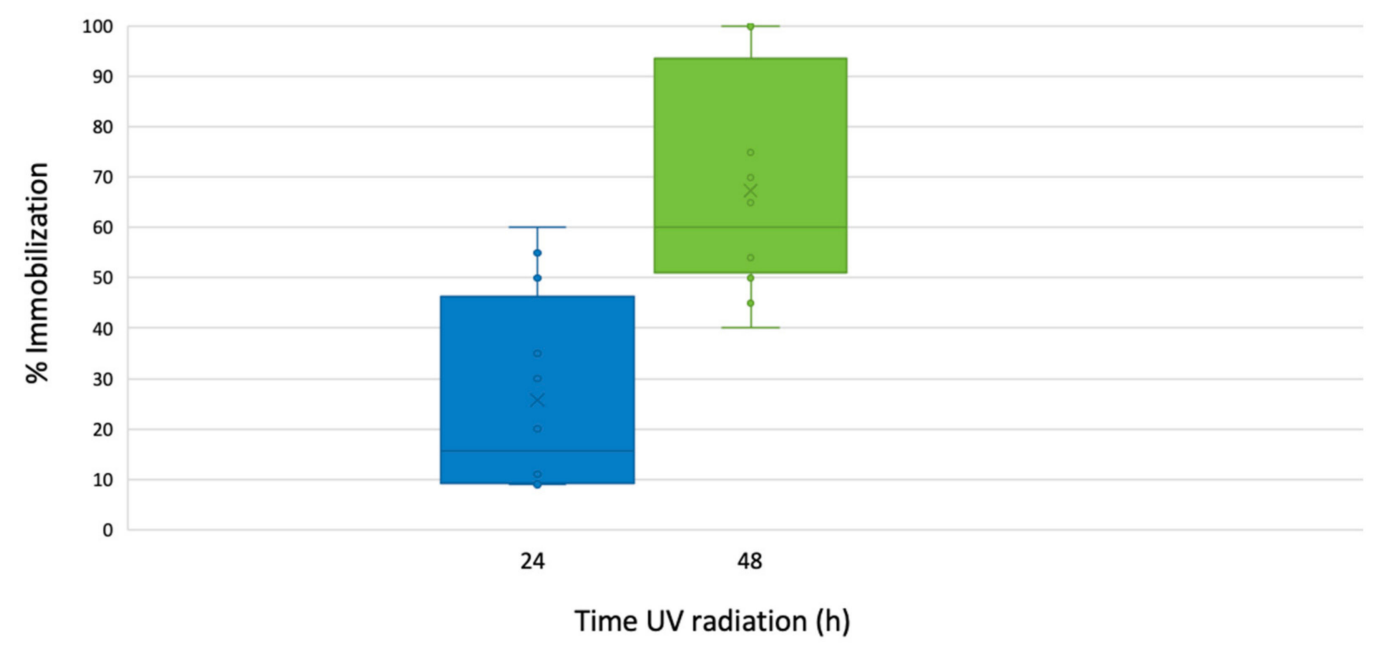

Figure 3. Percentage of immobilization for D. magna exposed to 24 and $48 \mathrm{~h}$ to SSR and $\mathrm{nTiO}_{2}$. The bars show the span of immobilization of the organism at $0.1,1,10$, and $100 \mathrm{mg} / \mathrm{L} \mathrm{nTiO}_{2}$.

As Artemia sp. habits in salty and hypersaline environments, it can quickly adapt to variations in salinity, ranging from $70 \%$ to $300 \%$, as stated by Amat et al., in 1983, the above allows the specimen to successfully face environmental adversities under extreme conditions. Given this characteristic, it was decided to combine $\mathrm{nTiO}_{2}$ with some organic UV filters (Table 2) because, in most sunscreens' formulations, a mixture of them is used. This mixture of UV filters, organic and inorganic substances, occurs in marine environments and could trigger different or similar toxicity mechanisms towards organisms as Artemia sp. [28].

Table 2. Combination of $\mathrm{nTiO}_{2}$ and organic UV filters mix used in the joint exposure bioassay with Artemia sp.

\begin{tabular}{|c|c|c|c|}
\hline \multicolumn{4}{|c|}{ Combinations Used with Artemia sp. } \\
\hline & & Component & Concentration $(\mathrm{mg} / \mathrm{L})$ \\
\hline \multirow{16}{*}{$\begin{array}{c}\text { Concentrations of } \mathrm{nTiO}_{2} \text { in combination } \\
\text { with the concentration of the mixture of } \\
\text { UV filters }\end{array}$} & \multirow{4}{*}{ Mix 1} & $\mathrm{TiO}_{2}$ & 0.000018 \\
\hline & & BP3 & \multirow{3}{*}{0.01} \\
\hline & & OC & \\
\hline & & EtPABA & \\
\hline & \multirow{4}{*}{$\operatorname{Mix} 2$} & $\mathrm{TiO}_{2}$ & 0.1 \\
\hline & & BP3 & \multirow{3}{*}{0.1} \\
\hline & & $\mathrm{OC}$ & \\
\hline & & EtPABA & \\
\hline & \multirow{4}{*}{ Mix 3} & $\mathrm{TiO}_{2}$ & 1 \\
\hline & & BP3 & \multirow{3}{*}{1} \\
\hline & & OC & \\
\hline & & EtPABA & \\
\hline & \multirow{4}{*}{$\operatorname{Mix} 4$} & $\mathrm{TiO}_{2}$ & 10 \\
\hline & & BP3 & \multirow{3}{*}{3} \\
\hline & & OC & \\
\hline & & EtPABA & \\
\hline
\end{tabular}

The concentrations of $\mathrm{nTiO}_{2}$ selected for this bioassay were $0.000018,0.1,1$, and $10 \mathrm{mg} / \mathrm{L}$. Then from the solution containing BP3, OC, and EtPABA, we prepared solutions of $0.01,0.1,1$, and $3 \mathrm{mg} / \mathrm{L}$, and mixed them with $\mathrm{nTiO}_{2}$ (Table 2). The lowest concentrations of $\mathrm{nTiO}_{2}$ and the UV filters were combined in Mix 1, while in Mix 2 and Mix 3 the 
concentrations were equal for $\mathrm{nTiO}_{2}$ and UV filters. Finally, the two highest concentrations were mixed in Mix 4.

At the first $24 \mathrm{~h}$ of exposure, Artemia sp. showed immobilization $<20 \%$, even when exposed to the Mix 4, corresponding to the highest concentrations of $\mathrm{nTiO}_{2}$ and organic UV filters.

As shown in Figure 4, the lethal effects were recorded at $96 \mathrm{~h}$, the time set in the OECD, 2004. Artemia sp. showed an immobilization ratio under $20 \%$ in Mix 1 . Still, in Mix 2 and Mix 3, the immobilization remained from 16\% to 23\%. However, with Mix 4, the immobilization increased up to $35 \%$. Under $16 \mathrm{~h} \mathrm{SSR}$, concentration-dependent immobilization in Artemia sp. was observed after $96 \mathrm{~h}$ exposure (Figure 4), and the EC50 value was $52 \mathrm{mg} / \mathrm{L}$.

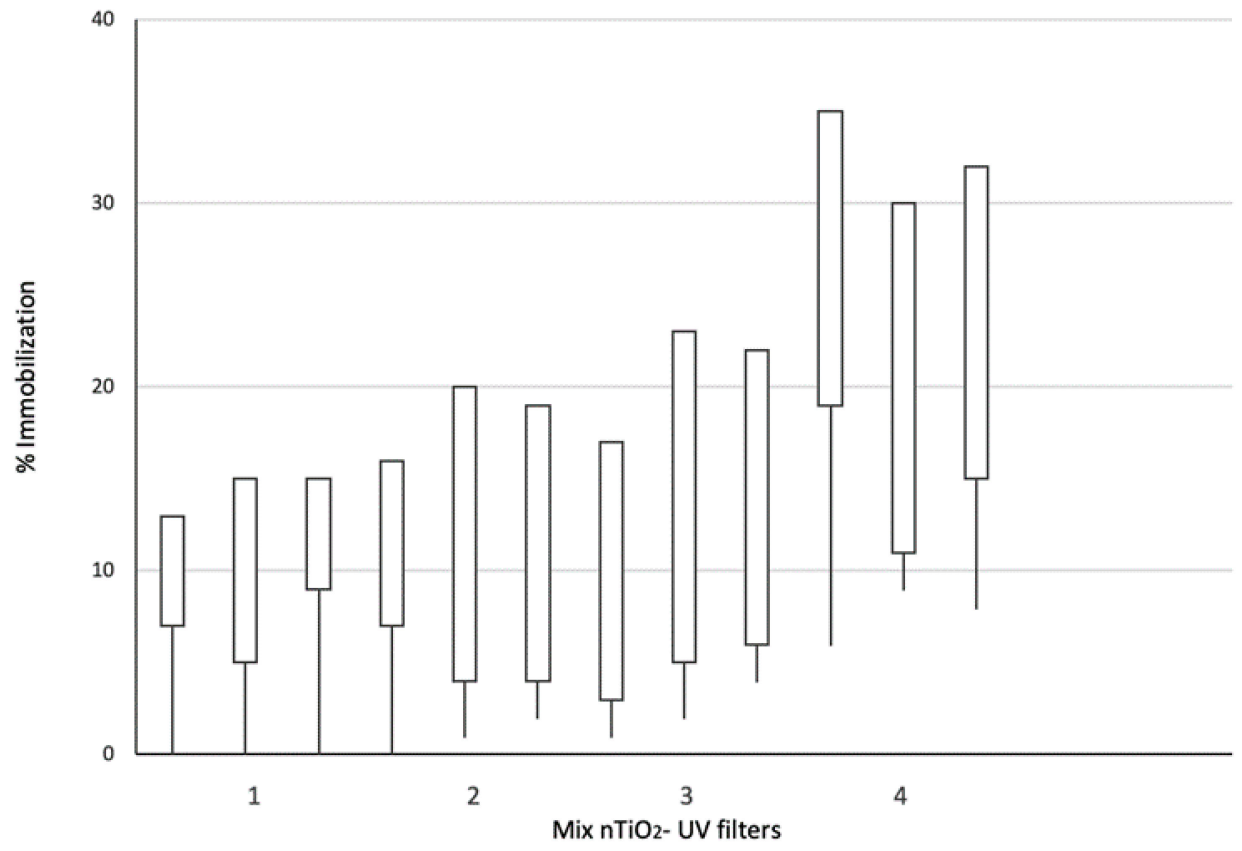

Figure 4. Artemia sp. exposed to a combination of $\mathrm{nTiO}_{2}$ and mixtures of $\mathrm{UV}$ organic filters, BP3, OC, and EtPABA and $16 \mathrm{~h}$ of SSR. The chart shows the increment of the immobilization in the three replicates per mix.

In the second bioassays, the Artemia sp. was exposed to $\mathrm{nTiO}_{2}$ and SSR, like as the third assay with $D$. magna (nTiO 2 concentrations of 0 (control), $0.000018,0.1,1,10,100 \mathrm{mg} / \mathrm{L}$, and $48 \mathrm{~h}$ UV radiation exposure). The Artemia sp. immobilization was then calculated at both $24 \mathrm{~h}$ and $48 \mathrm{~h}$ of irradiation with the presence of $\mathrm{nTiO}_{2}$ in the medium.

After the first $24 \mathrm{~h}$ and at concentrations of 0.1 and $1 \mathrm{mg} / \mathrm{L} \mathrm{nTiO}_{2}$, low immobilization was detected, $<10 \%$. Still, at $10 \mathrm{mg} / \mathrm{L} \mathrm{nTiO}$, immobile individuals were $20 \%$, and for $100 \mathrm{mg} / \mathrm{L}$ immobilization of 30\% was observed. The calculated EC50 was $62.33 \mathrm{mg} / \mathrm{L}$.

Then, after $48 \mathrm{~h}$ of UV radiation, a notable increase of the immobilization was observed (Figure 5), at $0.1 \mathrm{mg} / \mathrm{L}$ was $55 \%$. At 1 and $10 \mathrm{mg} / \mathrm{L} \mathrm{nTiO}{ }_{2}$ concentrations, the immobilization remained $<80 \%$, but almost $98 \%$ immobility was registered at $100 \mathrm{mg} / \mathrm{L}$, corresponding to a EC50 value of $7.60 \mathrm{mg} / \mathrm{L}$.

In all the acute toxicity tests with Artemia sp., survival in the control groups exceeded $90 \%$ after 48 h exposure. 


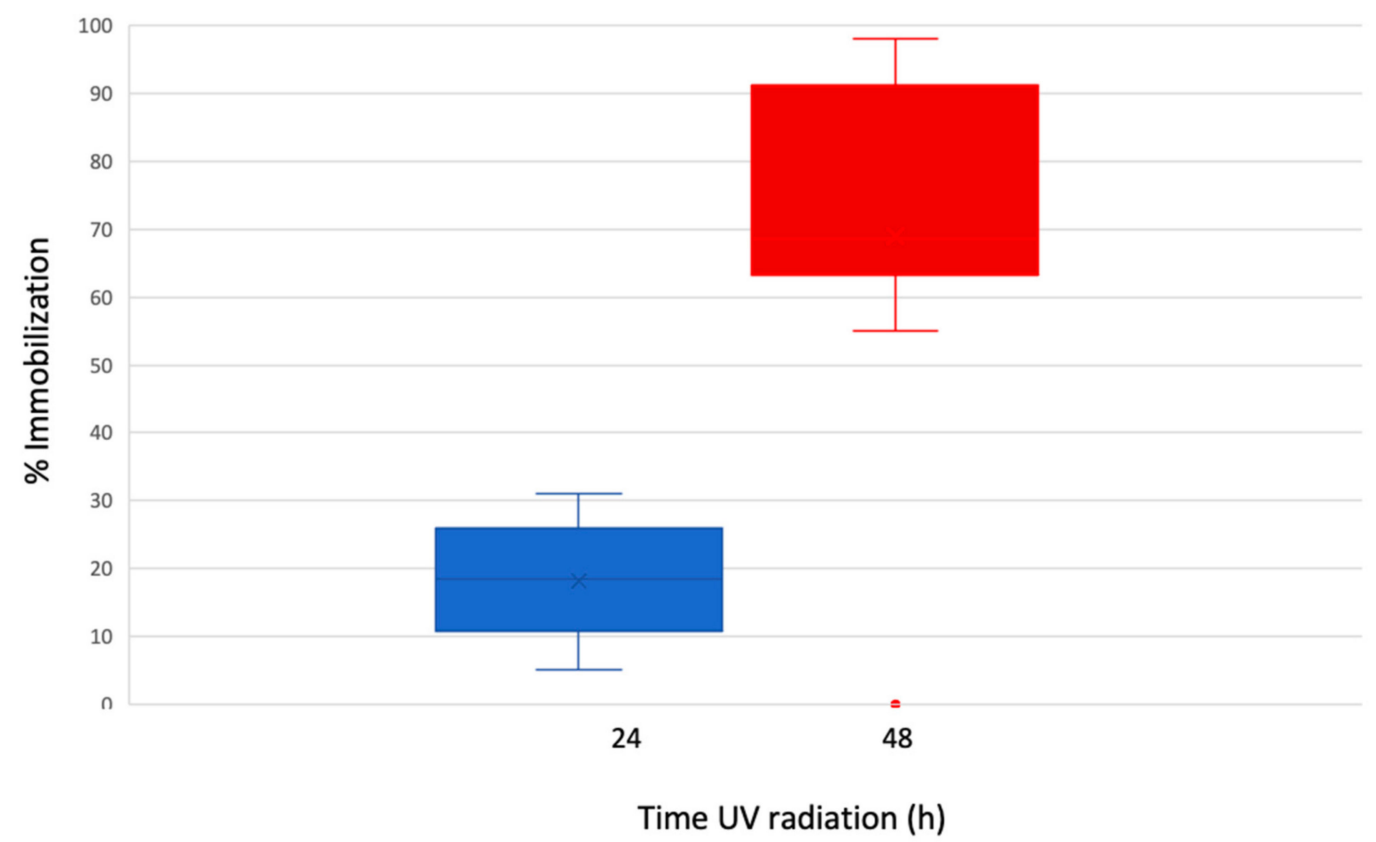

Figure 5. Percentage of immobilization for Artemia sp. exposed to 24 and $48 \mathrm{~h}$ of SSR and nTiO $\mathrm{O}_{2}$. The bars show the span of immobilization of the organism at $0.1,1,10$, and $100 \mathrm{mg} / \mathrm{L} \mathrm{nTiO}_{2}$.

\section{Discussion}

Two aquatic organisms, Daphnia magna and Artemia sp. were exposed to the combined effect of $\mathrm{nTiO}_{2}$ and SSR. The results showed that the toxicity of $\mathrm{nTiO}_{2}$ increased with UV light to the tested aquatic organisms (freshwater or seawater). The process of $\mathrm{nTiO}_{2}$ activation by UV light and subsequent formation of ROS in pure water is currently relatively well known [29].

Since $\mathrm{nTiO}_{2}$ are metal oxide nanoparticles, they are not biodegradable so will not lose their toxic properties but will persist in the environment. The $\mathrm{nTiO}_{2}$ form aggregates in aqueous environments; primary size aggregates can settle down and remain immobilized, while others are dispersed and become more mobile, bioavailable, and toxic. On the other hand, interaction with other particles and suspended organic matter is also supposed to modify their dynamic properties, and therefore, alter their toxicity.

So far, it has not been possible to predict the environmental or biological impacts of $\mathrm{nTiO}_{2}$ due to the complexity of the marine aquatic ecosystem, since in freshwater the behavior is different than in saltwater in terms of the aggregates that may form. It is known that in conventional wastewater treatment plants, the removal of these nanoparticles is not carried out due to their small size, which allows them to escape from conventional filters and membranes. Furthermore, the removal of $\mathrm{nTiO}_{2}$ through sedimentation is not viable. Nevertheless, the removal of the $\mathrm{nTiO}_{2}$ can be accomplished through ultrafiltration/nanofiltration, achieving 95\% removal efficiency.

Thus, the size and shape of the $\mathrm{nTiO}_{2}$ may influence toxicity, being so small, aquatic organisms may take $\mathrm{nTiO}_{2}$ as food and/or within the food. Besides this, interactions of substances at nanosize scale with other chemical/physical factors are greater than those usually established at the micron or higher scales, hence they can cause increased toxicity or other adverse effects in different marine species. Regarding the biological decomposition time, as already stated above, this cannot be due to decomposition because it is not biodegradable, and only can disperse or sediment.

Considering that the $\mathrm{nTiO}_{2}$ are in contact with other particles in the medium that influence aggregation behavior, the concentration of $\mathrm{nTiO}_{2}$ is also a key factor governing the behavior of this material in aqueous media. In particular, in our study, the sedimentation 
in freshwater was achieved after 10 to $15 \mathrm{~h}$, whereas, the sedimentation in saltwater ranged from 20 to $24 \mathrm{~h}$ at the concentration selected.

As $\mathrm{TiO}_{2}$ is a semiconductor material, UV radiation excites its electrons from the valence band to the conduction band, resulting in the generation of an electron-hole $(\mathrm{e}-/ \mathrm{h}+)$ pair. In this situation, the reduction of aqueous dissolved oxygen by $\mathrm{e}-$ and oxidation of water by $h+$ typically leads to the formation of primary ROS such as superoxide and hydroxyl radical, respectively. Once formed, these may lead to the generation of other oxidant species such as singlet oxygen or hydrogen peroxide.

In seawater, mechanisms as mentioned above are likely different, highlighting that high concentrations of halide species (mainly chlorine and bromide anions) would trigger the photocatalytic process to the generation of reactive halogen species $[3,13]$.

Previously, phototoxicity bioassays were conducted with Artemia sp. and demonstrated that this organism is resistant to diverse toxics. Still, in our study, when Artemia sp. was exposed to $\mathrm{nTiO}_{2}$ in combination with organic UV filters and high concentrations of $\mathrm{nTiO}_{2}$, it showed an increased ratio of immobilization. In addition, with high concentrations of $\mathrm{nTiO}_{2}$ and expanded UV light exposure time [30].

These outcomes are in agreement with previous studies; Hund-Rinke and Simon [17], conducted tests involving UV irradiation in a medium containing $\mathrm{nTiO}_{2}, D$. magna, and algae, and they concluded that the photocatalytic activity damaged the organism causing a complete immobilization.

According to Matsuo [31], UVA irradiation at $365 \mathrm{~nm}$ for 60 to $100 \mathrm{~min}$ to the planktonic species Artemia salina or Chatonella Antigua, and $1 \mathrm{mg} / \mathrm{L}$ of $\mathrm{nTiO}_{2}$ caused immobilization in both organisms. Marcone [32] tested a combination of commercial $\mathrm{nTiO}_{2}(30 \%$ rutile and $70 \%$ anatase) at $100 \mathrm{mg} / \mathrm{L}$ and UVA radiation on $D$. magna. The findings suggested that $\mathrm{nTiO}_{2}$ phototoxicity under UV radiation was the principal cause of the acute toxic effect observed and that the corresponding EC50 value for D. magna was $5.50 \mathrm{mg} / \mathrm{L}$, similar to the value estimated in the present study. Ma [33], reported that there was a linear correlation between ROS production and D. magna immobilization and that ROS formation might be a predictor of the phototoxicity caused by $\mathrm{nTiO}_{2}$. This ROS production has been probed to cause sublethal oxidative stress in different organisms, such as fish embryos [34].

Concerning saline organisms, Artemia sp. was subjected to SSR and $\mathrm{nTiO}_{2}$ concentrations and showed an immobilization below 10\% in the first bioassay with an EC50 value of $94 \mathrm{mg} / \mathrm{L}$, opposite case with D. magna with the same exposition set up, $10 \mathrm{mg} / \mathrm{L}_{\text {of }} \mathrm{nTiO}_{2}$ and $16 \mathrm{~h}$ UV radiation, and an EC50 value of $6.4 \mathrm{mg} / \mathrm{L}$.

In the second bioassay performed at the same concentrations of $\mathrm{nTiO}_{2}$ but joined with BP3, OC, and EtPABA, three of the most toxic UV organic filters, this organism showed higher immobilization. Our findings suggested that when the UV irradiation exposure and the concentration of $\mathrm{nTiO}_{2}$ increase, even when $\mathrm{nTiO}_{2}$ is combined with the mixture of organic UV filters, the $96 \mathrm{~h} \mathrm{EC50} \mathrm{was} 52 \mathrm{mg} / \mathrm{L}$, indicating low toxicity through the combined effects.

Despite that, concerns have been raised about the occurrence of mixtures of $\mathrm{nTiO}_{2}$ and organic UV filters in seawater, because of the interaction among these substances, sunlight and halide anions, which may result in the photocatalytic generation of RHS and subsequent halogenation of the organic compounds [3]. Also, previous studies suggested that the organic UV filters are less photostable (except for oxybenzone), resulting in photolysis and harmful free-oxygen radicals [35].

In the third set of assays with Artemia sp., the organism exhibited low immobilization when exposed to $24 \mathrm{~h}$ continuous radiation. The immobilization ratio was less than $30 \%$. Then, when Artemia sp. continued to be exposed to UV radiation up to $48 \mathrm{~h}$, the immobilization started at low concentration, and 60\% immobility was observed. At a higher concentration $(100 \mathrm{mg} / \mathrm{L})$, enhanced phototoxicity was registered. This exponential increase in mortality observed may be explained by the extended time at which the organisms were exposed to ROS and RHS. 
Aquatic organisms like D. magna incorporate $\mathrm{nTiO}_{2}$ via the gut [36]. Artemia sp. is a filter feeder, and then the nanoparticles may enter their guts through ingestion [37]. The mortality observed may be due to the uptake of the $\mathrm{nTiO}_{2}$ in combination with SSR.

The above might be conducted to the organism's oxidative stress of the organisms besides the ROS and RHS originated during the exposure. According to Ma [38], the mode of action associated with phototoxicity is SSR, which activates ionic or respiratory stress caused by damage to respiratory and ion-exchanged surfaces by ROS produced when attached or adsorbed $\mathrm{nTiO}_{2}$.

Therefore, the findings suggested that the increasing concentration of $\mathrm{nTiO}_{2}$ and the long exposure time to solar radiation cause phototoxicity in D. magna and Artemia sp.

\section{Conclusions}

The present study investigated the phototoxicity of $\mathrm{nTiO}_{2}$ toward two aquatic organisms. D. magna that served as a model organism for a conservative risk assessment of freshwater, and Artemia sp. for saltwater organisms.

D. magna showed as a sensitive organism, and Artemia sp. showed as a resistant organism. Still, the latest showed a different behavior when it was exposed to $\mathrm{nTiO}_{2}$ joined with UV organic filters.

This work describes several bioassays with combinations of experimental conditions, it covers from the lowest concentration of $0.000018 \mathrm{mg} / \mathrm{L}$ to a higher concentration of $100 \mathrm{mg} / \mathrm{L}$, and it was demonstrated that $\mathrm{UV}$ radiation exposure time of 24 and $48 \mathrm{~h}$, might increase the phototoxicity of the $\mathrm{nTiO}_{2}$.

Also, the results achieved in this study regarding the toxic effects produced by combined stressors exposing on Artemia sp. guarantees subsequent investigations on joint effects when physical and chemical UV filters are combined.

Our findings evidence the increased toxicity of $\mathrm{nTiO}_{2}$ in aquatic environments under solar radiation, and especially when organic sunscreens are simultaneously present. This study also demonstrated the importance of considering not only the concentration of $\mathrm{nTiO}_{2}$ to assess its toxicity but also to consider other factors, i.e., sunlight and co-existing substances to estimate its environmental hazard. Reactive oxygen and halogen species formation in the photoreaction process are involved in the phototoxicity of $\mathrm{nTiO}_{2}$. Thus, significantly different phototoxic effects could be expected in natural waters with large differences in salts content, as is the case between freshwater and seawater.

From the results obtained in the present study, it can be concluded that:

On D. magna:

(I) Toxicity on this organism was increased when $\mathrm{nTiO}_{2}$ and irradiation were combined.

(II) When the UV irradiation time is extended, the phototoxicity potential of the $\mathrm{nTiO}_{2}$ increases at higher concentrations.

(III) A concentration-dependent immobilization process was observed in the simultaneous exposure to $48 \mathrm{~h}$ of $\mathrm{UV}$ irradiation at $100 \mathrm{mg} / \mathrm{L} \mathrm{nTiO}_{2}$.

On Artemia sp.:

(I) Exposure to short irradiation time and low $\mathrm{nTiO}_{2}$ showed no phototoxicity.

(II) Exposure to irradiation, $\mathrm{nTiO}_{2}$, and a mixture of organic UV filters, a notorious increment of the immobilization rate was observed.

(III) A concentration-dependent immobilization process was observed when this organism was exposed to $48 \mathrm{~h}$ of $\mathrm{UV}$ radiation and $100 \mathrm{mg} / \mathrm{L}$ of $\mathrm{nTiO}_{2}$.

Author Contributions: A.C.S.d.I.V., A.C.-A., C.S.M., C.B.M., and M.S.D.-C. contributed to the study conception and design. Material preparation, data collection, and analysis were performed by A.C.S.d.1.V. and A.C.-A. The essential organism was provided by C.B.M. The first draft of the manuscript was written by A.C.S.d.I.V., C.S.M., C.B.M., and M.S.D.-C. supervised all the study and commented on previous versions of the manuscript. All authors have read and agreed to the published version of the manuscript. 
Funding: This research received external funding from the Spanish Ministry of Science and Innovation, AGAUR-Gencat and CONACyT.

Institutional Review Board Statement: Not applicable.

Informed Consent Statement: Not applicable.

Data Availability Statement: Data sharing not applicable. No new data were created or analyzed in this study.

Acknowledgments: Authors acknowledge the financial support of the Spanish Ministry of Science and Innovation, for projects ROUSSEAU (CTM2017-89767-C3-1-R), CEX2018-000794-S, and CTQ201786466-R., and AGAUR-Gencat project 2017SGR131. A.C. Soler acknowledges Mexican CONACyT for her doctoral grant (Ref. 409154).

Conflicts of Interest: The authors declare no conflict of interest.

$\begin{array}{ll}\text { Abbreviations } & \\ \text { Artemia sp. } & \text { A.sp. } \\ \text { Benzophenone 3 } & \mathrm{BP3} \\ \text { Daphnia magna } & \text { D. magna } \\ \text { Dynamic light scattering } & \mathrm{DLS} \\ \text { Ethyl 4-aminobenzoate } & \text { EtPABA } \\ \text { Median Effective Concentration } & \mathrm{EC50} \\ \text { Methanol } & \mathrm{MeOH} \\ \text { Nano-particles of titanium dioxide } & \mathrm{nTiO} 2 \\ \text { Octocrylene } & \mathrm{OC} \\ \text { Reactive halogen species } & \mathrm{RHS} \\ \text { Reactive oxygen species } & \mathrm{ROS} \\ \text { Simulated solar radiation } & \mathrm{SSR} \\ \text { Titanium Dioxide } & \mathrm{TiO} \\ \text { Transmission electron microscopy } & \mathrm{TEM} \\ \text { Ultraviolet } & \mathrm{UV} \\ \text { Ultraviolet A } & \mathrm{UVA} \\ \text { Ultraviolet C } & \mathrm{UVC}\end{array}$

\section{References}

1. Roco, M.C. Erratum to: The long view of nanotechnology development: The National Nanotechnology Initiative at 10 years. J. Nanopart. Res. 2011, 13, 1335. [CrossRef]

2. Piccinno, F.; Gottschalk, F.; Seeger, S.; Nowack, B. Industrial production quantities and uses of ten engineered nanomaterials in Europe and the world. J. Nanoparticle Res. 2012, 14, 1109.

3. Ohno, T.; Sarukawa, K.; Tokieda, K.; Matsumura, M. Morphology of a $\mathrm{TiO}_{2}$ Photocatalyst (Degussa, P-25) Consisting of Anatase and Rutile Crystalline Phases. J. Catal. 2001, 203, 82-86. [CrossRef]

4. Schulz, J.; Hohenberg, H.; Pflücker, F.; Gärtner, E.; Will, T.; Pfeiffer, S.; Wepf, R.A.; Wendel, V.; Gers-Barlag, H.; Wittern, K.-P. Distribution of sunscreens on skin. Adv. Drug Deliv. Rev. 2002, 54, S157-S163. [CrossRef]

5. Gamer, A.; Leibold, E.; Van Ravenzwaay, B. The in vitro absorption of microfine zinc oxide and titanium dioxide through porcine skin. Toxicol. Vitr. 2006, 20, 301-307. [CrossRef] [PubMed]

6. Cross, S.E.; Innes, B.; Roberts, M.S.; Tsuzuki, T.; Robertson, T.A.; McCormick, P. Human Skin Penetration of Sunscreen Nanoparticles: In-vitro Assessment of a Novel Micronized Zinc Oxide Formulation. Skin Pharmacol. Physiol. 2007, 20, 148-154. [CrossRef]

7. Sánchez-Quiles, D.; Tovar-Sánchez, A. Are sunscreens a new environmental risk associated with coastal tourism? Environ. Int. 2015, 83, 158-170. [CrossRef]

8. Boxall, A.B.A.; Rudd, M.A.; Brooks, B.W.; Caldwell, D.J.; Choi, K.; Hickmann, S.; Innes, E.; Ostapyk, K.; Staveley, J.P.; Verslycke, T.; et al. Pharmaceuticals and Personal Care Products in the Environment: What Are the Big Questions? Environ. Heal. Perspect. 2012, 120, 1221-1229. [CrossRef]

9. Whatmore, R.W. Nanotechnology-What is it? Should we be worried? Occup. Med. 2006, 56, 295-299. [CrossRef]

10. Brunet, L.; Lyon, D.Y.; Hotze, E.M.; Alvarez, P.J.J.; Wiesner, M.R. Comparative Photoactivity and Antibacterial Properties of C60Fullerenes and Titanium Dioxide Nanoparticles. Environ. Sci. Technol. 2009, 43, 4355-4360. [CrossRef]

11. Menard, A.; Drobne, D.; Jemec, A. Ecotoxicity of nanosized $\mathrm{TiO}_{2}$. Review of in vivo data. Environ. Pollut. 2011, 159, 677-684. [CrossRef] [PubMed]

12. Schneider, R.J.; Roe, K.L.; Hansel, C.M.; Voelker, B.M. Species-Level Variability in Extracellular Production Rates of Reactive Oxygen Species by Diatoms. Front. Chem. 2016, 4, 5. [CrossRef] [PubMed] 
13. Hao, Z.; Yin, Y.-G.; Wang, J.; Cao, D.; Liu, J. Formation of organobromine and organoiodine compounds by engineered $\mathrm{TiO}_{2}$ nanoparticle-induced photohalogenation of dissolved organic matter in environmental waters. Sci. Total Environ. 2018, 631-632, 158-168. [CrossRef] [PubMed]

14. Porcar-Santos, O.; Cruz-Alcalde, A.; López-Vinent, N.; Zanganas, D.; Sans, C. Photocatalytic degradation of sulfamethoxazole using $\mathrm{TiO}_{2}$ in simulated seawater: Evidence for direct formation of reactive halogen species and halogenated by-products. Sci. Total. Environ. 2020, 736, 139605. [CrossRef]

15. Okupnik, A.; Pflugmacher, S. Oxidative stress response of the aquatic macrophyte Hydrilla verticillata exposed to TiO ${ }_{2}$ nanoparticles. Environ. Toxicol. Chem. 2016, 35, 2859-2866. [CrossRef]

16. Cherchi, C.; Gu, A.Z. Impact of Titanium Dioxide Nanomaterials on Nitrogen Fixation Rate and Intracellular Nitrogen Storage in Anabaena variabilis. Environ. Sci. Technol. 2010, 44, 8302-8307. [CrossRef]

17. Hund-Rinke, K.; Simon, M. Ecotoxic Effect of Photocatalytic Active Nanoparticles $\left(\mathrm{TiO}_{2}\right)$ on Algae and Daphnids (8 pp). Environ. Sci. Pollut. Res. 2006, 13, 225-232. [CrossRef]

18. Wiench, K.; Wohlleben, W.; Hisgen, V.; Radke, K.; Salinas, E.; Zok, S.; Landsiedel, R. Acute and chronic effects of nano- and non-nano-scale $\mathrm{TiO}_{2}$ and $\mathrm{ZnO}$ particles on mobility and reproduction of the freshwater invertebrate Daphnia magna. Chemosphere 2009, 76, 1356-1365. [CrossRef]

19. De la Vega, A.C.S.; Molins-Delgado, D.; Barceló, D.; Díaz-Cruz, M.S. Nanosized titanium dioxide UV filter increases mixture toxicity when combined with parabens. Ecotoxicol. Environ. Saf. 2019, 184, 109565. [CrossRef]

20. Barata, C.; Baird, D.J. Phenotypic plasticity and constancy of life-history traits in laboratory clones of Daphnia magna Straus: Effects of neonatal length. Funct. Ecol. 1998, 12, 442-452. [CrossRef]

21. Bustos, N.; Cruz-Alcalde, A.; Iriel, A.; Cirelli, A.F.; Sans, C. Sunlight and UVC-254 irradiation-induced photodegradation of organophosphorus pesticide dichlorvos in aqueous matrices. Sci. Total Environ. 2019, 649, 592-600. [CrossRef] [PubMed]

22. Gottschalk, F.; Sun, T.; Nowack, B. Environmental concentrations of engineered nanomaterials: Review of modeling and analytical studies. Environ. Pollut. 2013, 181, 287-300. [CrossRef] [PubMed]

23. Gago-Ferrero, P.; Díaz-Cruz, M.S.; Barceló, D. An overview of UV-absorbing compounds (organic UV filters) in aquatic biota. Anal. Bioanal. Chem 2012, 404. [CrossRef] [PubMed]

24. Gadelha, J.R.; Rocha, A.C.; Camacho, C.; Eljarrat, E.; Peris, A.; Aminot, Y.; Readman, J.W.; Boti, V.I.; Nannou, C.; Kapsi, M.; et al. Persistent and emerging pollutants assessment on aquaculture oysters (Crassostrea gigas) from NW Portuguese coast (Ria De Aveiro). Sci. Total Environ. 2019, 666, 731-742. [CrossRef] [PubMed]

25. Lovern, S.B.; Klaper, R. Daphnia magna mortality when exposed to titanium dioxide and fullerene (c60) nanoparticles. Environ. Toxicol. Chem. 2006, 25, 1132-1137. [CrossRef] [PubMed]

26. Kim, K.-T.; Klaine, S.J.; Kim, S.D. Acute and Chronic Response of Daphnia magna Exposed to TiO 2 Nanoparticles in Agitation System. Bull. Environ. Contam. Toxicol. 2014, 93, 456-460. [CrossRef] [PubMed]

27. Johari, S.; Asghari, S. Acute toxicity of titanium dioxide nanoparticles in Daphnia magna and Pontogammarus maeoticus. J. Adv. Environ. Health Res. 2015, 3, 111-119. [CrossRef]

28. Amador-Castro, F.; Rodriguez-Martinez, V.; Carrillo-Nieves, D. Robust natural ultraviolet filters from marine ecosystems for the formulation of environmental friendlier bio-sunscreens. Sci Total. Environ. 2020, 749, 141576. [CrossRef]

29. Ahamed, A.; Liang, L.; Lee, M.Y.; Bobacka, J.; Lisak, G. Too small to matter? Physicochemical transformation and toxicity of engineered $\mathrm{nTiO}_{2}, \mathrm{nSiO}_{2}, \mathrm{nZnO}$, carbon nanotubes, and nAg. J. Hazard. Mater. 2021, 404, 124107. [CrossRef]

30. Clemente, Z.; Castro, V.L.; Jonsson, C.M.; Fraceto, L.F. Minimal levels of ultraviolet light enhance the toxicity of TiO ${ }_{2}$ nanoparticles to two representative organisms of aquatic systems. J. Nanopart. Res. 2014, 16, 2559. [CrossRef]

31. Matsuo, S.; Anraku, Y.; Yamada, S.; Honjo, T.; Matsuo, T.; Wakita, H. Effects of photocatalytic reactions on marine plankton: Titanium dioxide powder as catalyst on the body surface. J. Environ. Sci. Heal. Part. A 2001, 36, 1419-1425. [CrossRef] [PubMed]

32. Marcone, G.P.; Oliveira, A.C.; Almeida, G.; Umbuzeiro, G.D.A.; Jardim, W.F. Ecotoxicity of $\mathrm{TiO}_{2}$ to Daphnia similis under irradiation. J. Hazard. Mater. 2012, 211-212, 436-442. [CrossRef] [PubMed]

33. Ma, H.; Brennan, A.; Diamond, S.A. Photocatalytic reactive oxygen species production and phototoxicity of titanium dioxide nanoparticles are dependent on the solar ultraviolet radiation spectrum. Environ. Toxicol. Chem. 2012, 31, 2099-2107. [CrossRef] [PubMed]

34. Faria, M.; Navas, J.M.; Soares, A.M.V.M.; Barata, C. Oxidative stress effects of titanium dioxide nanoparticle aggregates in zebrafish embryos. Sci. Total Environ. 2014, 470, 379-389. [CrossRef]

35. Karlsson, H.L.; Gustafsson, J.; Cronholm, P.; Möller, L. Size-dependent toxicity of metal oxide particles-A comparison between nano- and micrometer size. Toxicol. Lett. 2009, 188, 112-118. [CrossRef]

36. Zhu, X.; Chang, Y.; Chen, Y. Toxicity and bioaccumulation of $\mathrm{TiO}_{2}$ nanoparticle aggregates in Daphnia magna. Chemosphere 2010, 78, 209-215. [CrossRef]

37. Ates, M.; Daniels, J.; Arslan, Z.; Farah, I.O. Effects of aqueous suspensions of titanium dioxide nanoparticles on Artemia salina: Assessment of nanoparticle aggregation, accumulation, and toxicity. Environ. Monit. Assess. 2012, 185, 3339-3348. [CrossRef]

38. Ma, H.; Brennan, A.; Diamond, S.A. Phototoxicity of $\mathrm{TiO}_{2}$ nanoparticles under solar radiation to two aquatic species: Daphnia magna and Japanese medaka. Environ. Toxicol. Chem. 2012, 31, 1621-1629. [CrossRef] [PubMed] 